\title{
AVALIAÇÃO DAS CONCENTRAÇÕES DE INÓCULO E DE MELAÇO DE SOJA NA PRODUÇÃO DE BIOSUSFACTANTE.
}

\author{
A. L. M. CASTRO ${ }^{1}$, B. C. DE CARVALHO GOMES ${ }^{1}$, M. S. RODRIGUES ${ }^{1}$, V. L. \\ CARODOSO $^{1}$, M. M. DE RESENDE ${ }^{1}$ \\ ${ }^{1}$ Universidade Federal de Uberlândia, Faculdade de Engenharia Química \\ E-mail para contato: mresende@ufu.br
}

\begin{abstract}
RESUMO - No presente trabalho utilizou-se Pseudomonas Aeruginosa ATCC 9027 e o melaço de soja para a produção de biosurfactante. A fermentação foi realizada nas concentrações de melaço de soja de $100 \mathrm{~g} / \mathrm{L}$ e $250 \mathrm{~g} / \mathrm{L}$ e em duas concentrações de inóculo 0,6 e 1,0 g/L. A linhagem de Pseudomonas aerugina 9027 estudada apresentou produção de biossurfactante, com a presença de emulsões estáveis após 24 horas e o biossurfactante, produzido não se apresentou como bom redutor da tensão superficial nas concentrações encontradas.
\end{abstract}

\section{INTRODUÇÃ̃O}

Os surfactantes são substâncias anfifílicas, possuem uma parte hidrofóbica e outra hidrofílica. São classificados em quatro grupos, de acordo com a carga iônica da parte polar da molécula, aniônicas, não iônicas, anfóteras e catiônicas. Apresentam como características principais a redução da tensão superficial e interfacial, ação emulsificante, solubilizante e formação de micelas. Um dos índices mais utilizados para determinar a eficiência de um surfactante é a concentração micelar crítica, que é a concentração mínima de surfactante necessária para atingir a menor tensão superficial ou interfacial de uma fase aquosa (DESAI e BANAT, 1997; MULLIGAN, 2005).

De forma distinta aos surfactantes, os biossurfactantes são classificados de acordo com sua estrutura química e origem microbiana. Os principais grupos são: glicolipídeos, lipopetídeos, fosfolipídeos, ácidos graxos e lipídeos neutros, biossurfactantes poliméricos e surfactantes particulados (LANG, 2002).

Os raminolipídeos são biossurfactantes do grupo dos glicolipídeos e produzidos por bactérias do tipo Pseudomonas aeruginosa, formados pela ligação de uma molécula de raminose a uma ou duas moléculas de ácido $\beta$-hidroxidecanóico. Essa é uma classe de biossurfactante bastante atrativa a qual apresenta capacidade para reduzir a tensão superficial, emulsionar hidrocarbonetos e pode ser produzida em meios de cultivo com hidrocarbonetos ou carboidratos como única fonte de carbono (ROSEMBERG e RON, 1999; HOLMBERG, 2001).

Apesar de todas as vantagens que os biossurfactantes apresentam, o elevado custo de sua produção acaba tornando um empecilho para utilização em escala industrial. Para reduzir 
esse custo, uma alternativa é a utilização de resíduos agroindustriais como substrato para produção dos biossurfactantes (MESQUITA, 2004).

O Brasil destaca-se como o principal exportador de soja sendo o segundo maior produtor, ficando atrás apenas dos Estados Unidos, tornando a soja um agronegócio de fundamental importância na economia brasileira (EMBRAPA, 2015; KAMALI et al., 2016). O processamento da soja ocorre em diversas etapas e um dos produtos desejados é o concentrado proteico de soja. Concomitante a esta etapa ocorre a produção do melaço de soja, rico em carboidratos e produzido a partir da extração alcoólica dos açúcares presentes no farelo desengordurado (JOHNSON et al., 1992).

\section{MATERIAL E MÉTODOS}

O presente trabalho utilizou as culturas de Pseudomonas Aeruginosa ATCC 9027 provenientes da Coleção de Culturas Tropicais da Fundação André Tosello em Campinas, SP. O substrato utilizado na fermentação foi o melaço de soja, oriundo da empresa de beneficiamento de soja Selecta em Araguari-MG.

As bactérias foram armazenadas em tubos de ensaio com meio gelose, cuja composição foi em (g/L): Sacarose 20,0; Peptona de carne bacteriológica 5,0; Extrato de carne 3,0 e Ágar bacteriológico 20,0. Para o repique quinzenal, as bactérias foram transferidas para um novo tubo contendo o meio e foram entubadas por 48 horas a $30^{\circ} \mathrm{C}$. Posteriormente, foram mantidas refrigeradas a fim de reduzir seu metabolismo.

A fermentação foi realizada em duas diferentes concentrações de melaço de soja diluídas em água destilada $100 \mathrm{~g} / \mathrm{L}$ e $250 \mathrm{~g} / \mathrm{L}$ e em duas concentrações de inóculo 0,6 e 1,0 g/L de Pseudomonas Aeruginosa ATCC 9027. Os experimentos foram realizados em Erlenmeyers de 250 $\mathrm{mL}$ contendo $150 \mathrm{~mL}$ de melaço nas concentrações citadas. $\mathrm{O} \mathrm{pH}$ inicial foi ajustado em 7,0. Os Erlenmeyers foram agitados a $120 \mathrm{rpm}$ em temperatura de $30 \pm 1{ }^{\circ} \mathrm{C}$ por um período total de 72 horas em skaker com controle de temperatura.

O índice de emulsificação foi realizado utilizando $3 \mathrm{~mL}$ de óleo de soja e $2 \mathrm{~mL}$ da amostra sobrenadante colocados em um tubo de ensaio de vidro. Este tubo foi agitado vigorosamente por 2 minutos em um agitador de tubos Vortex. Após a agitação, o tubo permaneceu em repouso por 24 horas. Após este tempo o índice de Emulsificação foi medido e seu resultado apresentado em porcentagem.

A análise de tensão superficial foi realizada utilizando cerca de $10 \mathrm{~mL}$ de meio em uma placa de Petri a qual foi colocada no Tensiômetro Educacional K6 da marca Láctea previamente calibrado. O tensiômetro foi utilizado com um anel de platina-iridium de $2 \mathrm{~cm}$ de diâmetro e $6 \mathrm{~cm}$ de altura.

A massa seca foi determinada pela centrifugação da amostra fermentada. Após a retirada do sobrenadante a amostra foi levada a estufa a $80^{\circ} \mathrm{C}$ por 24 horas em uma placa de Petri previamente pesada.

$\mathrm{Na}$ determinação da concentração de biossurfactante presente, foram adicionados $2 \mathrm{~mL}$ da amostra e $2 \mathrm{~mL}$ de acetato de etila em um tubo de ensaio de vidro com rosca e agitado em Vortex por 2 minutos. Após ocorrer a separação de fases, retirou-se $1 \mathrm{~mL}$ do sobrenadante e mediu-se a 


\section{Congresso Brasileiro de Engenharia Química \\ em Iniciação Científica \\ UFSCar - São Carlos - SP \\ 16 a 19 de Julho de 2017}

CONGRESSO BRASILEIRO DE ENGENHARIA

massa seca a $80^{\circ} \mathrm{C}$ por 24 horas. A quantificação da concentração de biossurfactante foi realizada pela diferença do peso final e inicial, expressa em gramas por litro.

\section{RESULTADOS E DISCUSSÕES}

As análises realizadas foram: biomassa (BM), concentração de biossurfactante (CB), índice de emulsificação (IE) e tensão superficial (TS). A Figura 3.1 mostra o comportamento do crescimento celular para cada uma das condições citadas acima. Nela é possível notar que o crescimento celular foi maior para a concentração de $250 \mathrm{~g} / \mathrm{L}$ nas duas condições em relação às de $100 \mathrm{~g} / \mathrm{L}$, uma vez que as bactérias dispunham de maior quantidade de carboidratos, lipídeos, dentre outros por possuírem maior concentração dos mesmos.

Figura 3.1 - Biomassa (BM) ao longo do tempo para as condições de $100 \mathrm{~g} / \mathrm{L}$ de melaço de soja no meio e $0,6 \mathrm{~g} / \mathrm{L}$ de Pseudomonas aeruginosa $9027 ; 100 \mathrm{~g} / \mathrm{L}$ de melaço de soja no meio e 1,0 g/L de Pseudomonas aeruginosa 9027; $250 \mathrm{~g} / \mathrm{L}$ de melaço de soja no meio e 0,6 g/L de Pseudomonas aeruginosa 9027 e $250 \mathrm{~g} / \mathrm{L}$ de melaço de soja no meio e 1,0 g/L de Pseudomonas aeruginosa 9027.

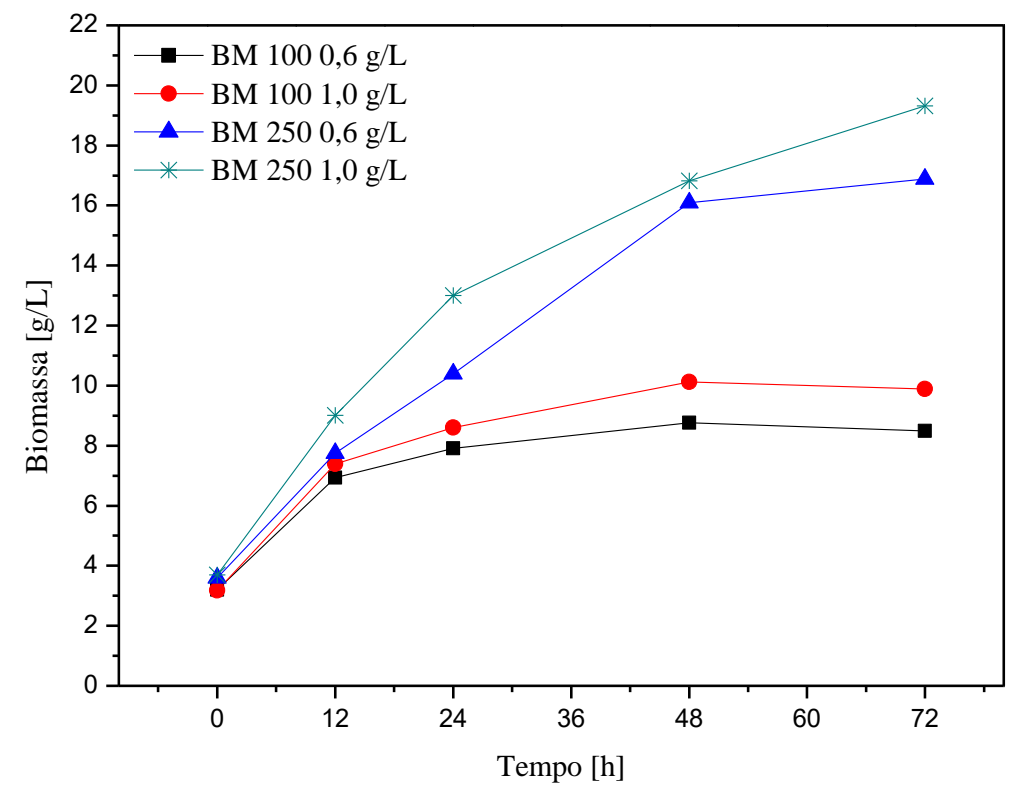

A Figura 3.2 apresenta os dados da concentração de biossurfactante ao longo do tempo, assim como na figura anterior, as condições com maior concentração de melaço apresentaram maiores valores da concentração de biossurfactante no meio. $\mathrm{O}$ crescimento ocorreu principalmente nas primeiras 24 horas, após esse período manteve-se constante ou com pequena variação. O comportamento das concentrações de $100 \mathrm{~g} / \mathrm{L}$ foi semelhante independente da concentração inicial de microrganismo. De forma análoga para as concentrações de $250 \mathrm{~g} / \mathrm{L}$, porém a concentração final de biossurfactante foi maior para a condição, cuja concentração inicial de microrganismo é menor.

Figura 3.2 - Concentração de biossurfactante (CB) ao longo do tempo para as condições de 100 g/L de melaço de soja no meio e 0,6 g/L de Pseudomonas aeruginosa 9027; 100 g/L de melaço de soja no meio e 1,0 g/L de Pseudomonas aeruginosa 9027; 250 g/L de melaço de 
soja no meio e 0,6 g/L de Pseudomonas aeruginosa 9027 e 250 g/L de melaço de soja no meio e 1,0 g/L de Pseudomonas aeruginosa 9027.

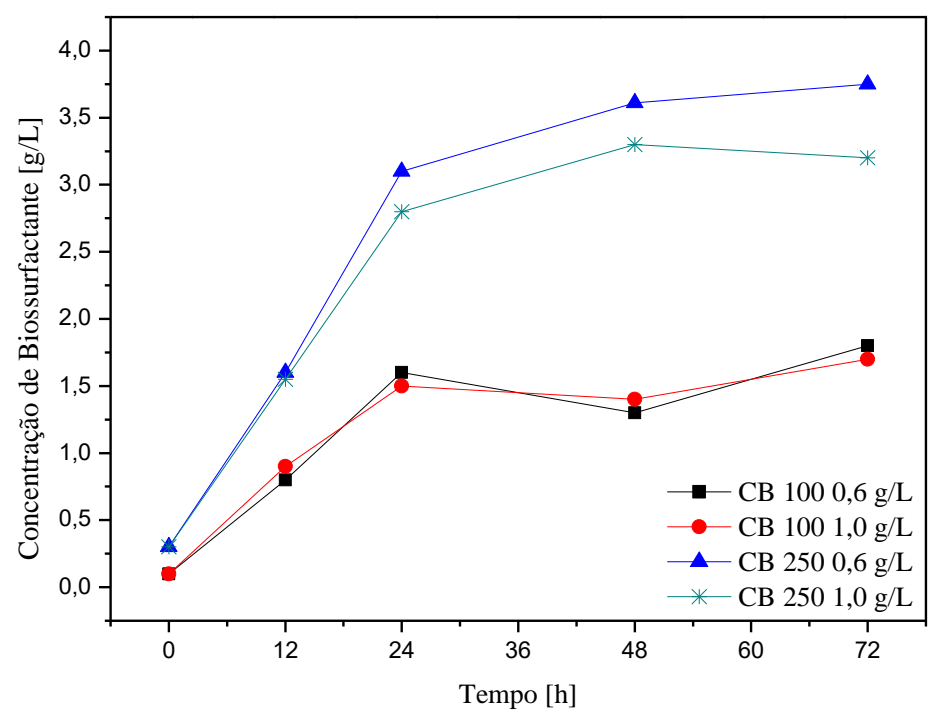

A Figura 3.3 mostra o comportamento do índice de emulsificação ao longo do tempo. As emulsões apresentaram valores significativos nas primeiras 12 horas, após esse período apenas a concentração de $100 \mathrm{~g} / \mathrm{L}$ aumentou apresentando índices de até $70 \%$ de emulsificação, as outras condições permaneceram constantes ou variaram pouco. Já a Figura 3.5 mostrou que houve grande variação nos valores da tensão superficial, tendo atingido redução dos valores próximo a 24 horas e posterior aumento, apresentando instabilidade independente das concentrações avaliadas. Os valores iniciais da tensão superficial apontam que o melaço de soja possui componentes capazes de reduzir a tensão superficial do meio. Desta forma, pelo comportamento apresentado pelas Figuras 3.1 a 3.4 é possível notar que houve produção de biossurfactante por Pseudomonas aerugina 9027, porém o biossurfactante produzido mostrou emulsões estáveis após 24 horas e não se apresentou como bom redutor da tensão superficial.

Ramírez et al. (2015) produziu biossurfactantes usando óleo de moinho residual como única fonte de carbono e obteve $191,46 \mathrm{mg} / \mathrm{L}$ de concentração de biossurfactante na concentração de $10 \% \mathrm{~m} / \mathrm{v}$ do substrato utilizado.

De acordo com Haba et al. (2000) podem ser considerados bons produtores de biossurfactantes aqueles microrganismos que reduzem a tensão superficial a menos de 40 dyne $/ \mathrm{cm}$. Para Banat et al. (2010) a capacidade dos biossurfactantes para formarem emulsões estáveis pode melhorar o processo de eficiência para a recuperação de óleos de poços de petróleo

Figura 3.3 - Índice de emulsificação (IE) ao longo do tempo para as condições de $100 \mathrm{~g} / \mathrm{L}$ de melaço de soja no meio e 0,6 g/L de Pseudomonas aeruginosa 9027; $100 \mathrm{~g} / \mathrm{L}$ de melaço de soja no meio e 1,0 g/L de Pseudomonas aeruginosa $9027 ; 250 \mathrm{~g} / \mathrm{L}$ de melaço de soja no meio e $0,6 \mathrm{~g} / \mathrm{L}$ de Pseudomonas aeruginosa 9027 e $250 \mathrm{~g} / \mathrm{L}$ de melaço de soja no meio e 1,0 g/L de 


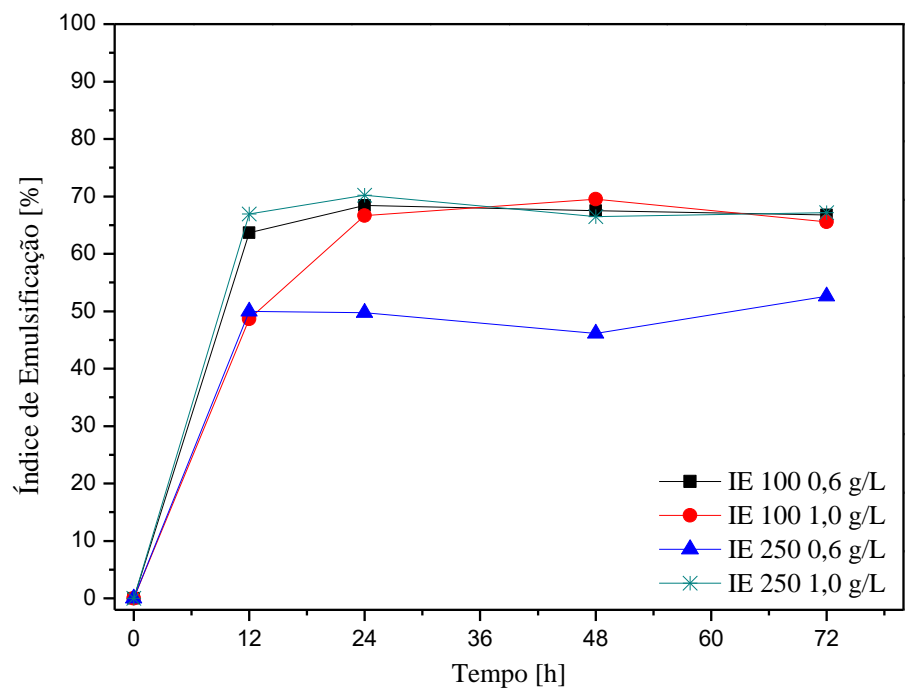

Figura 3.4 - Tensão superficial (TS) ao longo do tempo para as condições de $100 \mathrm{~g} / \mathrm{L}$ de melaço de soja no meio e 0,6 g/L de Pseudomonas aeruginosa 9027; $100 \mathrm{~g} / \mathrm{L}$ de melaço de soja no meio e 1,0 g/L de Pseudomonas aeruginosa $9027 ; 250 \mathrm{~g} / \mathrm{L}$ de melaço de soja no meio e $0,6 \mathrm{~g} / \mathrm{L}$ de Pseudomonas aeruginosa 9027 e $250 \mathrm{~g} / \mathrm{L}$ de melaço de soja no meio e 1,0 g/L de Pseudomonas aeruginosa 9027.

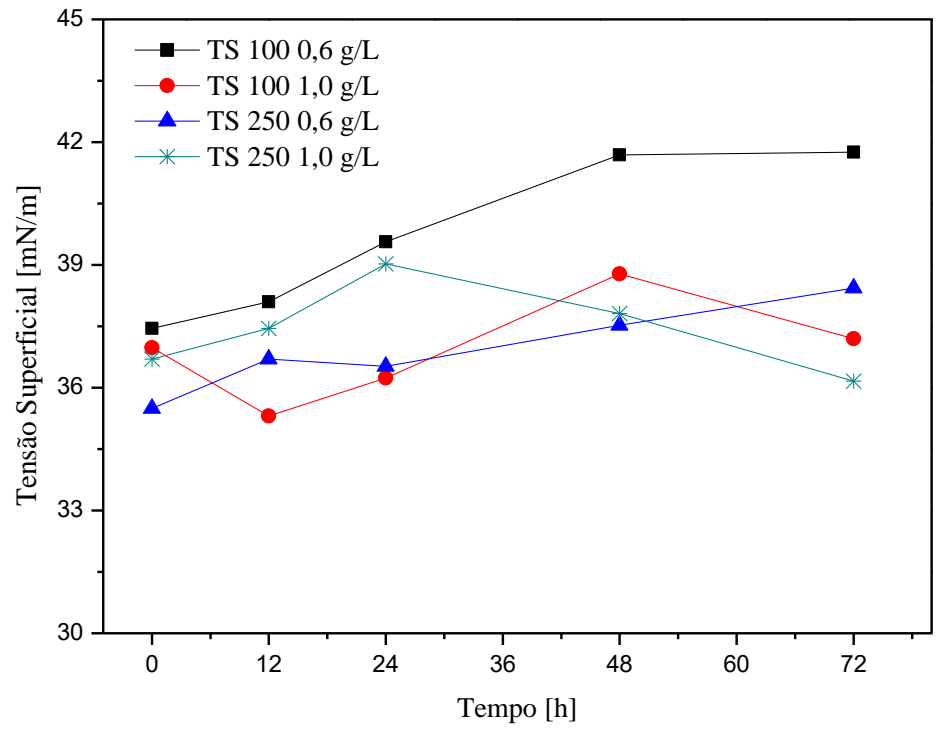

\section{CONCLUSÕES}

A linhagem de Pseudomonas aerugina 9027 apresentou produção de biossurfactante, com a presença de emulsões estáveis após 24 horas e o biossurfactante, produzido não se apresentou como bom redutor da tensão superficial nas concentrações encontradas. 


\section{AGRADECIMENTOS}

Os autores agradecem à UFU, CAPES, CNPq e FAPEMIG pelo apoio para realização deste trabalho.

\section{REFERÊNCIAS}

BANAT, I. M., FRANZETTI, A., GANDOLFI, I., BESTETTI, G., MARINOTTI, M. G., FRACCHIA, L., SMYTH, T. J., MARCHANT, R. Microbial biosurfactants production, applications and future potencial. Appl. Microbiol. Biotechnol., v. 87, p. 427-444, 2010.

DESAI, J. D.; BANAT, I. M. Microbial production os surfactant and their comercial potential. Microbiol. Mol. Biol. R., v. 61, p.47-64, 1997.

EMBRAPA - Empresa Brasileira de Pesquisa Agropecuária. Disponível em: < https://www.embrapa.br/soja/cultivos/soja1/historia> acesso em 07 de dezembro de 2015.

HABA E, ESPUNY MJ, BUSQUETS M, MANRESA A (2000) Screening and production of rhamnolipids by Pseudomonas aeruginosa 47 T2 NCIB 40044 from waste frying oils. $J$ Appl Microbiol, Oxford, v. 88, p. 379-387.

HOLMBERG, K. Natural Surfactants. Current Opinion in Colloid and Interface Science, v. 6, p. 148-159, 2001.

JOHNSON, L.A., MYERS, D.J., BURDEN, D.J. Soy Protein's History. Prospectis in Food, Feed. Inform 3:429-444, 1992.

KAMALI, F. P.; MEUWISSEN, M. P. M.; BOER, I. J. M.; VAN MIDDELAAR, C. E.; MOREIRA, A.; OUDE LANSINK, A. G. J. M. Evaluation of the environmental, economic, and social performance of soybean farming systems in southern Brazil. Journal of Cleaner Production, p. 1-10, 2016

LANG, S. Biological Amphiphiles: Microbial Surfactants. Opinion in Colloid and Interface Science, v. 74, p. 59-70, 2002.

MESQUITA, A. C. Uso das Técnicas de Oxidação Química e Biodegradação na Remoção de Alguns Componentes Recalcitrantes. Tese de Doutorado, UFRJ, 2004, 158p.

MULLIGAN, C. N.; Environmental Applications for Biosurfactants. Environmental Pollution, v. 133, p. 183-198, 2005.

RAMIRÉZ, I. M.; TSAOUSI, K.; RUDDEN, M.; MARCHANT, R.; ALAMEDA, E. J.; ROMÁN, M. G.; BANAT, I. M. Rhamnolipid and surfactin production from olive oil mil waste as sole carbono source. Bioresource Technology. V. 198, p. 231-236, 2015.

ROSENBERG, E.; RON, E. Z. High and low-molecular-mass microbial surfactants. Applied Microbiol. Biotechnol., v. 52 (2), p. 154-162, 1999. 